\title{
Position-specific countermovement jump characteristics of elite Women's Rugby World Cup 2017 athletes
}

\author{
Shane M. Heffernan ${ }^{1,{ }^{*}}$, Ross Neville ${ }^{2}$, Mark Waldron ${ }^{1,3,4}$, Ryan Stewart ${ }^{2}$, Liam P. Kilduff ${ }^{1,3}$, \\ Massimiliano Ditroilo ${ }^{2}$, and Adam Grainger ${ }^{2}$ \\ 1 Applied Sport Technology Exercise and Medicine Research Centre (A-STEM), College of Engineering, Swansea University, \\ Swansea, Wales \\ 2 School of Public Health, Physiotherapy and Sports Science, University College Dublin, Dublin, Ireland \\ ${ }^{3}$ Welsh Institute of Performance Science (WIPS), College of Engineering, Swansea University, Swansea, Wales \\ ${ }^{4}$ School of Science and Technology, University of New England, Armidale, New South Wales, Australia
}

Received 8 December 2020, Accepted 5 June 2021

\begin{abstract}
Rugby union (RU) is an intermittent team sport, with diverse playing positions, played internationally by both men and women. Considerable scientific attention has been devoted to men's RU, however despite the growth in the women's professional game, there is a significant lack of available physiological and normative data. The purpose of the present study was to investigate positional variation in countermovement jump characteristics from elite women's RU players. Qualitative data were collected from women's Rugby World Cup (2017) competitors $(\mathrm{n}=86$; age: $27 \pm 5$ years; body mass: $77.8 \pm 10.6 \mathrm{~kg}$; height: $1.69 \pm 0.07 \mathrm{~cm}$ ) and jump data (countermovement jumps) were collected using a $1200 \mathrm{~Hz}$ force platform $(\mathrm{n}=63)$. Athletes were divided into positional unit (backs: $\mathrm{n}=39$ and forwards: $\mathrm{n}=47)$ and by positional subgroups. Backs had greater jump height $(\mathrm{ES}=0.72,95 \% \mathrm{CL} \pm 0.50)$, relative power output $(\mathrm{ES}=0.84,95 \%$ $\mathrm{CL} \pm 0.50)$, relative force production $(\mathrm{ES}=0.62,95 \% \mathrm{CL} \pm 0.51)$ and reactive strength index $(\mathrm{RSI} ; \mathrm{ES}=0.62$, $95 \% \mathrm{CL} \pm 0.50$ ), compared to forwards (for all, $P<0.02$ ). Backrows, halves and back-three players had greater relative force, relative power and jump height, compared to the front and second rows $(P<0.03 ; \mathrm{ES}>0.70)$. These data could aid in programming for long-term player development in women's RU and could have implications for "readiness" to compete at international level.
\end{abstract}

Key words: jump kinematics, elite female athletes, power output

Résumé - Caractéristiques des sauts de contre-mouvement spécifiques à la position des athlètes d'élite de la Coupe du monde de rugby féminin 2017. Le rugby à XV (RU) est un sport d'équipe intermittent, avec des positions de jeu diverses, joué au niveau international par des hommes et des femmes. Une attention scientifique considérable a été consacrée au RU masculin, mais malgré la croissance du jeu professionnel féminin, il existe un manque important de données physiologiques et normatives disponibles. Le but de la présente étude était d'étudier la variation de position des caractéristiques des sauts avec contremouvement chez les joueuses élites de RU. Des données qualitatives ont été collectées auprès des compétiteurs de la Coupe du monde de rugby féminin (2017) ( $\mathrm{n}=86$; âge : $27 \pm 5$ ans ; masse corporelle : $77,8 \pm 10,6 \mathrm{~kg}$; taille : $1,69 \pm 0,07 \mathrm{~cm}$ ) et les données de saut (sauts avec contre-mouvement) ont été collectées à l'aide d'une plateforme de force de $1200 \mathrm{~Hz}(\mathrm{n}=63)$. Les athlètes ont été divisés en unités de position (arrière $: \mathrm{n}=39$ et avant : $\mathrm{n}=47)$ et en sous-groupes de position. Les arrières avaient des valeurs plus élevées de hauteur de saut $(\mathrm{ES}=0,72,95 \%$ $\mathrm{CL} \pm 0,50)$, de puissance de sortie relative $(\mathrm{ES}=0,84,95 \% \mathrm{CL} \pm 0,50)$, de production de force relative $(\mathrm{ES}=0,62,95 \% \mathrm{CL} \pm 0,51)$ et d'indice de résistance réactive ( $\mathrm{RSI} ; \mathrm{ES}=0,62,95 \% \mathrm{CL} \pm 0,50)$, par rapports aux avants (pour tous, $P<0,02$ ). Les joueurs d'arrière-plan, de moitié et d'arrière-trois avaient une force relative, une puissance relative et une hauteur de saut plus grandes que les joueurs de première ligne et de deuxième ligne $(P<0,03 ; \mathrm{ES}>0,70)$. Ces données pourraient aider à programmer le développement à long terme des joueurs dans le RU féminin et pourraient avoir des implications pour la préparation à la compétition au niveau international.

Mots clés : cinématique de saut, athlètes féminines d'élite, puissance de sortie

\footnotetext{
*Corresponding author: s.m.heffernan@swansea.ac.uk
} 


\section{Introduction}

Rugby union (RU) in both the men's and women's game requires high levels of strength, power, speed, aerobic and anaerobic fitness (Cunningham et al., 2018; Roberts, Trewartha, Higgitt, El-Abd, \& Stokes, 2008; Sheppy et al., 2019; Twist \& Worsfold, 2015). Data from the elite men's game show that athletes are required to develop and maintain high force-velocity dominant characteristics (Cross et al., 2014; Sedeaud et al., 2012). These demands differ in magnitude and specificity depending on the diverse positional units of backs and forwards, and diverge further considering the individual requirements of specific positional sub-groups (15-a-side game; Quarrie, Hopkins, Anthony, \& Gill, 2013; Smart, Hopkins, \& Gill, 2013). While these game demands are starting to be understood in the women's game, and appear to be relatively similar to the men's game (covering similar total distances throughout 80 mins; $\sim 6000 \mathrm{~m}$ match $^{-1}$ ) (Sheppy et al., 2019), phenotypic differences are well documented in the men's game (Brazier et al., 2018; Cahill, Lamb, Worsfold, Headey, \& Murray, 2013; Deutsch, Kearney, \& Rehrer, 2007; Quarrie et al., 2013; Roberts et al., 2008; Smart, Hopkins, Quarrie, \& Gill, 2014); however, little is known of elite women's RU (Hene, Bassett, \& Andrews, 2011; Hene \& Bassett, 2013; Sheppy et al., 2019). Thus limiting our understanding of the physiological requirements.

Since the introduction of women's RU (1994), participation has risen exponentially (World Rugby, 2018), amplified by the inclusion of the 7-a-side game (7's) to the modern Olympic games (IOC, 2017) and the recent, but not yet ubiquitous, introduction of professionalism (England Rugby, 2019). World Rugby estimates that there are currently 2.4 million female RU players world-wide (World Rugby, 2018), which represents a considerable proportion of overall participation $(>25 \%$ of $\sim 9$ million). Due to the inclusion of women's 7's in the Olympic games (2016), the physiological demands of International women's 7's players has been relatively well characterised (Agar-Newman, Goodale, \& Klimstra, 2017; Clarke, Anson, \& Pyne, 2017; Goodale, Gabbett, Stellingwerff, Tsai, \& Sheppard, 2016; Malone, Earls, Shovlin, Eddy, \& Winkelman, 2018). These data show that, similar to the men's 7's game (Clarke et al., 2017), there are some, but few physiological differences between women's backs and forwards (higher mass relative quantities and sprint ability/capacity in the backs; Agar-Newman et al., 2017; Misseldine, Blagrove, \& Goodwin, 2018; Ohya et al., 2015). Although women's RU athlete's regularly interchange between 7's and 15's codes (although data on this is currently lacking), the position specific physiological requirements and game demands differ vastly and cannot be directly compared. While there are some data on the physiological characteristics of elite and non-elite women's 15's, they are limited and often consist of low and underpowered samples (Hene et al., 2011; Lockie et al., 2016; Nyberg \& Penpraze, 2016). Nonetheless, early attempts have been made to quantify game demands using accepted methodologies (Suarez-Arrones et al., 2014; Virr, Game, Bell, \& Syrotuik, 2014).

Time-motion analysis and Global Positioning System (GPS) data of International and top club-level women's $\mathrm{RU}$ athletes show similar game demands, in that backs travel greater distances, spend more time at walking speeds $\left(<6 \mathrm{~km} \cdot \mathrm{h}^{-1}\right)$ and sprinting $\left(>14 \mathrm{~km} \cdot \mathrm{h}^{-1}\right)$, while forwards spend more time at moderate intensities (Sheppy et al., 2019; Suarez-Arrones et al., 2014; Virr et al., 2014), similar to the relationship, but different in magnitude, to the men's game (walking speeds $\sim 7 \mathrm{~km} \cdot \mathrm{h}^{-1}$ and sprinting $\sim 28 \mathrm{~km} \cdot \mathrm{h}^{-1}$ ) (Quarrie et al., 2013). There appears to be no differences in heart rate response at international level, but at armature club level (Canadian Premier Division), backs spent less time at $>80$ maximum heart rate and had a work-to-rest ratio approximately twice that of forwards (data not available for International players; Virr et al., 2014). These data present evidence of positional differences in game demands at both elite and non-elite level that could be reflected in anthropometric and physical characteristics. However, in non-elite Scottish players $(\mathrm{n}=19)$, no difference in anthropometrics, 10-40 m sprint, agility or estimated $\dot{\mathrm{V}} \mathrm{O}_{2 \max }$ were identified between forwards and backs (although backs showed greater flexibility (Sit and Reach (cm), $16.3 \pm 9.1$ versus $28.9 \pm 4.1$, respectively; Nyberg \& Penpraze, 2016). In contrast, only one study has assessed phenotypic variation of elite players, in the South African 2010 World Cup preseason training squad (forwards $n=16$ and backs $n=19$ ). In these candidate international players, forwards had greater body mass $(\sim 16 \mathrm{~kg})$ and percentage fat mass $(\sim 4 \%)$, while backs had greater vertical jump height $(7 \mathrm{~cm})$, push-ups $\cdot \mathrm{min}^{-1}(\mathrm{n} \sim 8)$, quicker $10 \mathrm{~m}(\sim 0.2 \mathrm{~s})$ and $40 \mathrm{~m}(\sim 0.5 \mathrm{~s})$ sprint times (Hene et al., 2011). Interestingly, over a 32 week season in the same sample, sprint speed changed with high variability but vertical jump height remained consistent (Hene \& Bassett, 2013). This might suggest that explosive leg power is both a good positional differentiator and a possible route to performance monitoring in women's RU athletes. The lack of evidence, particularly at the elite/international level, makes it difficult for practitioners to rely on or refer to these data. Thus, a greater understanding of women's RU physical and jump kinetics are warranted. Therefore, the aims of the present study was to compare kinetic jump data between positional groups to potential identify positional differentiator in a representative sample of International Women's Rugby World Cup (2017) competitors.

\section{Methods}

\subsection{Experimental design}

A cross-sectional research design was used to investigate participant characteristics, anthropometric measures (height, body mass) and kinetic jump data derived from the countermovement jumps performed on a force platform. All testing was carried out during the 2017 
Women's Rugby World Cup in Dublin, Ireland and therefore athletes were intended to be trained to their most competitive performance level at the time of testing. All data were collected by an experienced senior Strength and Conditioning professional at the Institute for Sport and Health laboratories.

\subsection{Participants}

Sport science and medicine staffs from participating countries were approached to evaluate player and nation interest. Four nations agreed to participate and provided consent to recruit their athletes (knockout rankings between 5th and 10th place). Custom qualitative questionnaires were used to collect data on primary and secondary playing positions, international playing experience and highest competitive level $(n=86)$. Of the consenting athletes, jump kinetic data were collected from athletes $(n=63)$ during the two weeks prior to the first group game and forwarded for analysis. For the remaining athletes $(n=23)$, the jump data were either not collected, due to prior injury/scheduling conflicts, or following initial data quality assurance it was deemed unacceptable for further analysis. Athletes were divided into their positional units of forwards ( $n=34$; props, hookers, locks, flankers, number eights) and backs $(n=29$; scrum halves, fly halves, centres, wings, full backs) and subsequently divided into their positional sub-groups according to game demand data (Sheppy et al., 2019). Anthropometric measures (height and body mass) were taken using standard methods. All participants provided individual written informed consent (provided in the athletes native language, if requested) and ethical approval was granted by University College Dublin Institutional Review Board. This study was conducted in accordance with the Declaration of Helsinki (2013).

\subsection{Performance testing}

From a standing position, with hands resting on the hips and feet extended throughout the flight to prevent knee tucking, two countermovement jumps (CMJs) were performed prior to resistance or field training. Two jumps were separated by $\sim 90 \mathrm{~s}$ and the best performance (i.e. highest jump) was recorded and used for further analysis. A rapid countermovement was conducted by the participants descending until the knee angle reached approximately $90^{\circ}$, followed immediately by a vertical jump. Participants were instructed to jump "as high as possible". Prior to testing, athletes were instructed to perform a prescribed warm up jump routine, which included, lowerlimb mobility exercises and three sub-maximal CMJ efforts. Athletes were familiar (confirmed individually prior to jump) with the CMJ protocol, having performed it on a regular basis over preceding months.

All jumps were performed on a portable force platform at a sampling rate of $1200 \mathrm{~Hz}$ (HUR Labs, Tampere, Finland), variables were generated and initially analysed by custom software (Force Platform Software Suite,
Version 2.4.0, Tampere, Finland). The raw data were then exported to Microsoft Excel and analysed using a customised version of the template by (Chavda et al., 2018). Specifically, the instantaneous acceleration $\left(\mathrm{m} \cdot \mathrm{s}^{2}\right)$ was obtained by dividing each force value according to the following equation:

$$
\mathrm{A}_{\mathrm{i}}=\left(\mathrm{F}_{\mathrm{i}} / \mathrm{m}\right)-\mathrm{g},
$$

where $F_{i}$ is the instantaneous force measured in Newtons, $\mathrm{m}$ is the body mass of the jumper in kilograms, and $\mathrm{g}$ the gravity acceleration. The velocity $\mathrm{V}_{\mathrm{i}}\left(\mathrm{m} \cdot \mathrm{s}^{-1}\right)$ was calculated according to the following equation:

$$
\mathrm{V}_{\mathrm{i}}=\mathrm{V}_{\mathrm{i}-1}+\mathrm{A}_{\mathrm{i}} \cdot \mathrm{t}_{\mathrm{i}}
$$

where $\mathrm{V}_{\mathrm{i}-1}$ is the instantaneous velocity of the centre of mass at previous point in time and $t_{i}$ is a $1 / 1200$ of a second. The threshold for take-off and landing was set at $5 \mathrm{SD}$ above the force recorded during flight time. Jump height $(\mathrm{cm})$ was calculated as:

$$
\mathrm{JH}=\left(\mathrm{V}_{\mathrm{to}}{ }^{2} / 2 \cdot \mathrm{g}\right) 100,
$$

where $V_{\text {to }}$ is instantaneous velocity at take-off. Power was obtained by multiplying instantaneous force by instantaneous velocity and peak power $(\mathrm{W})$ was identified as the maximum instantaneous power value. Peak power was divided by body mass of the jumper to obtain relative peak power $\left(\mathrm{W} \cdot \mathrm{kg}^{-1}\right)$. Net peak force $(\mathrm{N})$ was identified as the peak force value preceding take-off minus force corresponding to body weight. This was also expressed per $\mathrm{kg}$ of body mass, i.e. relative net peak force $\left(\mathrm{N} \cdot \mathrm{kg}^{-1}\right)$. Reactive strength index $\left(\mathrm{m} \cdot \mathrm{s}^{-1}\right)$ was calculated as $\mathrm{JH}(\mathrm{m})$ divided by contact time (s, from start of movement to take-off) (Chavda et al., 2018).

\subsection{Statistical analysis}

Descriptive data are presented as means and standard deviations. Data were analysed using linear mixed models to perform pairwise comparisons by positional unit (Forwards vs. Backs) and sub-groups (Front Row vs. Second Row vs. Back Row vs. Halves vs. Centres vs. Back Three) allowing for unequal variances. The distributions of the jump data met the Shapiro-Wilk test criteria for normality $(\mathrm{P}>0.05)$. Skewness and kurtosis values for the jump data were also examined and deemed to be within the acceptable range (Tabachnick, Fidell, \& Ullman, 2014). No issues in uniformity of error were identified (Hopkins, Marshall, Batterham, \& Hanin, 2009), so log transformation was avoided. The magnitudes of the differences between groups were assessed by means of standardisation (Cohen, 1988; Hopkins, 2002). These standardised effect sizes (ES) were subsequently evaluated according to the following scale: $<0.2$, trivial; $0.2-0.6$, small; $0.6-1.2$, moderate; $1.2-2.0$, large; $>2.0$, very large (Hopkins et al., 2009). Bonferroni adjustments were applied to P-values for the multiple comparisons. For 
Table 1. Means, standard deviations, effects, confidence limits, and null-hypothesis difference between means from anthropometric, countermovement jump performance indicators and qualitative data, between women's RU backs and forwards.

\begin{tabular}{|c|c|c|c|c|}
\hline & \multirow{2}{*}{$\begin{array}{l}\text { Forwards } \\
\text { Mean } \pm \text { SD } \\
(\mathrm{n}=47)\end{array}$} & \multirow{2}{*}{$\begin{array}{l}\text { Backs } \\
\text { Mean } \pm \mathrm{SD} \\
(\mathrm{n}=39)\end{array}$} & \multicolumn{2}{|c|}{$\begin{array}{c}\text { Difference } \\
\text { (Forwards-Backs) }\end{array}$} \\
\hline & & & Effect $^{\mathrm{a}} 95 \% \mathrm{CL}$ & $P$-value \\
\hline Height (cm) & $171 \pm 6$ & $166 \pm 7$ & $0.74 \pm 0.43$ & 0.001 \\
\hline Weight (kg) & $83 \pm 11$ & $73 \pm 8$ & $1.10 \pm 0.51$ & $<0.0001$ \\
\hline Peak force $(\mathrm{N})$ & $1015 \pm 190$ & $1003 \pm 226$ & $0.09 \pm 0.51$ & 0.74 \\
\hline Relative peak force $(\mathrm{N} \cdot \mathrm{kg}-1)$ & $12.3 \pm 1.9$ & $13.8 \pm 2.7$ & $-0.62 \pm 0.51$ & 0.02 \\
\hline Peak power $(\mathrm{W})$ & $3204 \pm 373$ & $3161 \pm 437$ & $0.12 \pm 0.50$ & 0.68 \\
\hline Relative peak power $(\mathrm{W} \cdot \mathrm{kg}-1)$ & $39.2 \pm 4.8$ & $43.8 \pm 5.8$ & $-0.84 \pm 0.50$ & 0.001 \\
\hline Competed in 7's & $14(30)$ & $30(77)$ & - & - \\
\hline Secondary position & $30(64)$ & $29(76)$ & - & - \\
\hline Secondary position outside primary group & $21(45)$ & $18(47)$ & - & - \\
\hline
\end{tabular}

${ }^{a}$ Effect sizes are that of the mean differences between positional groups.

null-hypothesis testing, alpha level was set at $P<0.05$ and uncertainty expressed as 95\% confidence limits. All analysis were performed in Statistical Analysis System (Version 9.4, SAS Inc., Cary, NC). A priori statistical power calculation revealed a sample of $\mathrm{n}=60$ was required to compare jump variables of six positional groups $\left(\mathrm{ES}=0.5\right.$ and $1-\beta=0.80 ; \mathrm{G}^{*}$ Power version 3.1.9.3).

\section{Results}

\subsection{Participant characteristics}

Forwards were $5 \mathrm{~cm}$ taller and had $10 \mathrm{~kg}$ greater body mass compared to backs, with no difference in age. Sixtyfive percent of athletes had $<5$ years of international RU experience and $51 \%$ competed internationally in both the 7's and 15's game. Over two-thirds (69\%) reported a secondary playing position and $46 \%$ were "outside" of their primary positional group (Tab. 1).

\subsection{Main analysis}

There was a significant overall effect (by positional unit) for countermovement jump height $(P=0.005)$, relative peak force $(P=0.02)$, relative peak power $(P=0.001)$ and reactive strength index (RSI; $\mathrm{P}=0.01$ : Tab. 1). Backs had a greater jump height $(\mathrm{ES}=0.72,95 \%$ $\mathrm{CL} \pm 0.50)$, relative power output $(\mathrm{ES}=0.84,95 \% \mathrm{CL}$ $\pm 0.50)$, relative force production $(\mathrm{ES}=0.62,95 \% \mathrm{CL}$ $\pm 0.51)$ and RSI $(\mathrm{ES}=0.62,95 \% \mathrm{CL} \pm 0.50)$, compared to forwards. Differences between backs and forwards in respect of peak power output $(P=0.68 ; \mathrm{ES}=0.10,95 \%$ $\mathrm{CL} \pm 0.50)$ and net peak force production $(P=0.85$;
$\mathrm{ES}=0.05,95 \% \mathrm{CL} \pm 0.51 ;$ Tab. 1). The violin plots, accompanying pairwise comparisons, reveal bimodal and multimodal phenotypic variation when considering only backs and forwards (Fig. 1). Each of these plots suggests that there is variability in jump performance that is not adequately captured in the overall comparison of backs $v s$. forwards and deeper positional analysis was required.

For positional sub-groups, post-hoc comparisons revealed that athletes in the backrow, halves and back three had greater relative force production, relative power output and jump height, compared to the front and second row athletes $(\mathrm{ES}>0.70)$. Halves and back three athletes had greater RSI compared to front and second row athletes $(\mathrm{ES}>0.97)$ and front row athletes had a greater net peak force than second row athletes $(\mathrm{ES}=0.91, \pm 0.68$; Tab. 2$)$. A series of dot plots illustrate the extent of the variability in jump characteristics across sub-groups (Fig. 2). Numerical descriptive data for each of these jump characteristics by sub-group are presented in supplementary Table S1 for practitioner reference (Supplementary Table S1).

\section{Discussion}

The present study provides the first position-specific normative jump kinetic data in the largest sample of international Women's Rugby World Cup competitors to date. In addition to positional distinctions, the violin plots presented herein show bimodal and multimodal variation in jump characteristics between unit groups (backs and forwards). This highlights the importance of advancing current literature that is limited to unit comparisons in 

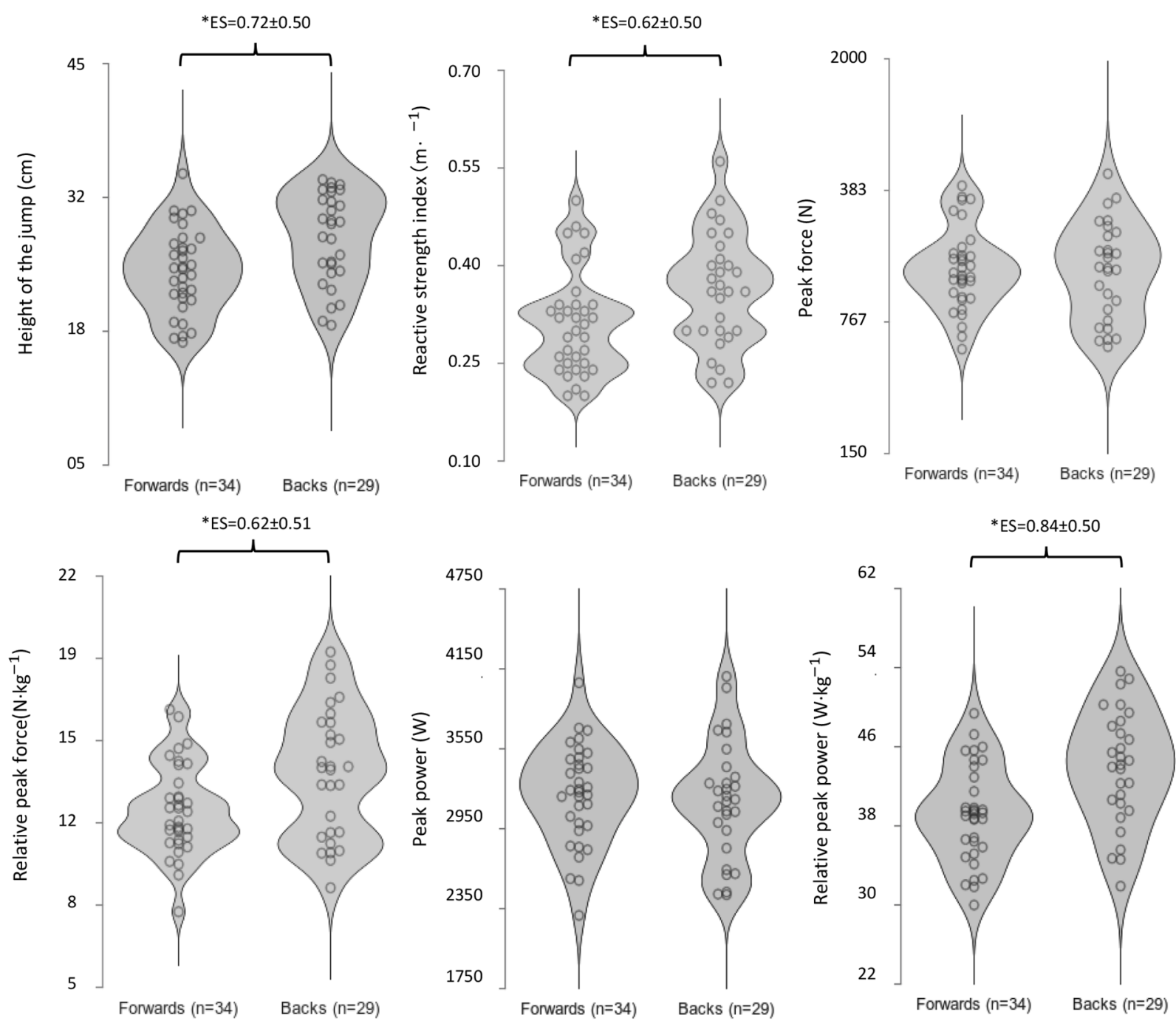

Fig. 1. Violin plots showing further positional variation embedded with the Backs and Forwards. "** indicates null-hypothesis difference $(p<0.05)$ and "ES" is the effect size (difference in means divided by the between-subjects SD at 95\%CL).

elite women's RU (Hene et al., 2011; Hene \& Bassett, 2013; Suarez-Arrones et al., 2014; Virr et al., 2014) and the need to investigate more specific positional variation. To address this limitation, the current study revealed that the front five athletes (front and second row groups) had lower jump heights, and most relative force and power than backrows, halves and back three athletes. Furthermore, front rows had greater net peak force and peak power which represented large effects than all other athlete groups.

Alongside a number of high-intensity dynamic activities, all RU athletes are required to perform demanding low-velocity efforts, such as scrums, mauls, rucks and lineouts (Deutsch et al., 2007; Smart et al., 2014). Whilst the frequency of these activities will vary across positional groups, these match demands require $\mathrm{RU}$ athletes to develop and maintain the capacity to produce high external forces, and translate this into over-ground tasks requiring high velocity and power (Cross et al., 2014). However, as with match demand metrics, these abilities are position specific and there is a considerable lack of knowledge regarding elite women's RU. The present data addresses some of these areas, demonstrating large differences in vertical jump parameters between positional groups, particular jump height and relative peak power/ force data. This reflects a similar relationship in elite men where, backs have higher relative power (i.e. when body mass is factored) compared to forwards (Front $5,49.4 \mathrm{~W} \cdot \mathrm{kg}^{-1}$ versus Back 3 and Centres, $59.8 \mathrm{~W} \cdot \mathrm{kg}^{-1}$ ), but is different from elite men in that forwards have higher absolute peak power (Heffernan et al., 2017). A likely rationale for the difference in absolute peak power, between the men's and women's game (that becomes significant when scaling for body mass), is the aforementioned relatively recent introduction of professionalism in the elite women's game (England Rugby, 2019) where the majority of current international players being semiprofessional/amateur athletes. It is well documented in the men's game that level-specific physiological characteristics can distinguish between semi-professional and professional players (Baker, 2001; Quarrie et al., 1995; Smart et al., 2013) and the present data reflects this mix 
Table 2. Effects, confidence limits and null-hypothesis difference between means from countermovement jump performance indicators in selected playing position.

\begin{tabular}{|c|c|c|c|c|}
\hline \multirow{3}{*}{ Jump height } & & & \multicolumn{2}{|c|}{ Difference } \\
\hline & \multicolumn{2}{|c|}{ Positional groups $^{\mathrm{a}}$} & \multirow{2}{*}{$\begin{array}{c}\text { Effect }^{\mathrm{b}}, 95 \% \mathrm{CL} \\
0.01 \pm 0.75\end{array}$} & \multirow{2}{*}{$\begin{array}{l}P \text {-value } \\
0.990\end{array}$} \\
\hline & Front row & Second row & & \\
\hline & " & Backrow & $-0.93 \pm 0.73$ & 0.029 \\
\hline & "'" & Halves & $-1.39 \pm 0.82$ & 0.006 \\
\hline & (') & Centres & $-0.67 \pm 0.99$ & 0.190 \\
\hline & "' & Back three & $-1.33 \pm 0.88$ & 0.013 \\
\hline & Second row & Backrow & $-0.94 \pm 0.74$ & 0.028 \\
\hline & "'" & Halves & $-1.39 \pm 0.83$ & 0.006 \\
\hline & " & Centres & $-0.67 \pm 1.00$ & 0.186 \\
\hline & “" & Back three & $-1.33 \pm 0.88$ & 0.013 \\
\hline & Backrow & Halves & $-0.45 \pm 0.82$ & 0.263 \\
\hline & " & Centres & $0.27 \pm 0.99$ & 0.581 \\
\hline & " & Back three & $-0.40 \pm 0.87$ & 0.369 \\
\hline & Halves & $\because "$ & $0.06 \pm 0.94$ & 0.902 \\
\hline & Centres & Halves & $-0.72 \pm 1.05$ & 0.175 \\
\hline & '"' & Back three & $-0.66 \pm 1.09$ & 0.234 \\
\hline \multirow[t]{15}{*}{ Reactive strength } & Front row & Second row & $0.08 \pm 0.70$ & 0.825 \\
\hline & (") & Backrow & $-0.54 \pm 0.75$ & 0.173 \\
\hline & "'" & Halves & $-1.10 \pm 0.99$ & 0.035 \\
\hline & "'" & Centres & $0.29 \pm 0.87$ & 0.493 \\
\hline & "'" & Back three & $-0.97 \pm 0.72$ & 0.023 \\
\hline & Second row & Backrow & $-0.62 \pm 0.81$ & 0.147 \\
\hline & "'" & Halves & $-1.18 \pm 1.02$ & 0.032 \\
\hline & "'" & Centres & $0.34 \pm 1.05$ & 0.414 \\
\hline & (") & Back three & $-1.04 \pm 0.77$ & 0.022 \\
\hline & Backrow & Halves & $-0.56 \pm 1.05$ & 0.270 \\
\hline & "' & Centres & $0.25 \pm 0.95$ & 0.599 \\
\hline & (') & Back three & $-0.43 \pm 0.82$ & 0.309 \\
\hline & Halves & “" & $0.13 \pm 1.03$ & 0.782 \\
\hline & Centre & Halves & $0.81 \pm 1.12$ & 0.152 \\
\hline & $" \%$ & Back three & $-0.67 \pm 0.93$ & 0.162 \\
\hline \multirow{15}{*}{ Peak force } & Front row & Second row & $0.91 \pm 0.68$ & 0.025 \\
\hline & '" & Backrow & $0.71 \pm 0.92$ & 0.150 \\
\hline & $" "$ & Halves & $1.13 \pm 1.47$ & 0.105 \\
\hline & "' & Centres & $0.45 \pm 1.04$ & 0.389 \\
\hline & "'" & Back three & $0.51 \pm 1.06$ & 0.353 \\
\hline & Second row & Backrow & $-0.20 \pm 0.76$ & 0.587 \\
\hline & "'? & Halves & $0.22 \pm 1.47$ & 0.697 \\
\hline & "'" & Centres & $-0.46 \pm 0.92$ & 0.301 \\
\hline & $" '$ & Back three & $-0.41 \pm 0.93$ & 0.377 \\
\hline & Backrow & Halves & $0.43 \pm 1.48$ & 0.521 \\
\hline & (') & Centres & $-0.26 \pm 1.08$ & 0.626 \\
\hline & "') & Back three & $-0.21 \pm 1.10$ & 0.706 \\
\hline & Halves & $\because "$ & $0.63 \pm 1.53$ & 0.382 \\
\hline & Centres & Halves & $0.68 \pm 1.52$ & 0.337 \\
\hline & (") & Back three & $-0.05 \pm 1.19$ & 0.928 \\
\hline \multirow[t]{4}{*}{ Peak power } & Front row & Second row & $0.49 \pm 0.67$ & 0.160 \\
\hline & (") & Backrow & $0.40 \pm 0.80$ & 0.320 \\
\hline & “' & Halves & $0.78 \pm 1.08$ & 0.128 \\
\hline & "') & Centres & $0.58 \pm 0.67$ & 0.111 \\
\hline
\end{tabular}


Table 2. (continued).

\begin{tabular}{|c|c|c|c|c|}
\hline \multirow{2}{*}{\multicolumn{5}{|c|}{ Positional groups ${ }^{\mathrm{a}}$}} \\
\hline & & Positional groups ${ }^{\mathrm{a}}$ & Effect $^{\mathrm{b}}, 95 \% \mathrm{CL}$ & $P$-value \\
\hline & "') & Back three & $0.21 \pm 0.85$ & 0.602 \\
\hline & Second row & Backrow & $-0.09 \pm 0.86$ & 0.829 \\
\hline & "'" & Halves & $0.29 \pm 1.11$ & 0.573 \\
\hline & (") & Centres & $0.09 \pm 0.76$ & 0.815 \\
\hline & (") & Back three & $-0.28 \pm 0.90$ & 0.514 \\
\hline & Backrow & Halves & $0.38 \pm 1.16$ & 0.495 \\
\hline & (") & Centres & $0.18 \pm 0.87$ & 0.678 \\
\hline & (") & Back three & $-0.18 \pm 0.99$ & 0.710 \\
\hline & Halves & '"' & $-056 \pm 1.19$ & 0.332 \\
\hline & Centres & Halves & $-0.20 \pm 1.11$ & 0.697 \\
\hline & "' & Back three & $-0.36 \pm 0.91$ & 0.429 \\
\hline \multirow[t]{15}{*}{ Relative peak force } & Front row & Second row & $0.50 \pm 0.60$ & 0.120 \\
\hline & (") & Backrow & $-0.23 \pm 0.81$ & 0.578 \\
\hline & " & Halves & $-0.62 \pm 1.25$ & 0.283 \\
\hline & " & Centres & $-0.56 \pm 1.18$ & 0.331 \\
\hline & " & Back three & $-0.86 \pm 1.02$ & 0.114 \\
\hline & Second row & Backrow & $-0.72 \pm 0.70$ & 0.057 \\
\hline & (") & Halves & $-1.12 \pm 1.23$ & 0.054 \\
\hline & "' & Centres & $-1.06 \pm 1.13$ & 0.066 \\
\hline & (") & Back three & $-1.36 \pm 0.94$ & 0.014 \\
\hline & Backrow & Halves & $-0.40 \pm 1.28$ & 0.503 \\
\hline & " & Centres & $-0.34 \pm 1.22$ & 0.570 \\
\hline & " $"$ & Back three & $-0.63 \pm 1.07$ & 0.251 \\
\hline & Halves & '" & $-0.23 \pm 1.38$ & 0.722 \\
\hline & Centres & Halves & $0.06 \pm 1.48$ & 0.930 \\
\hline & (") & Back three & $-0.30 \pm 1.34$ & 0.654 \\
\hline \multirow[t]{15}{*}{ Relative peak power } & Front row & Second row & $-0.01 \pm 0.67$ & 0.980 \\
\hline & " & Backrow & $-0.77 \pm 0.72$ & 0.056 \\
\hline & " & Halves & $-1.38 \pm 0.94$ & 0.011 \\
\hline & “" & Centres & $-0.60 \pm 0.84$ & 0.17 \\
\hline & '" & Back three & $-1.51 \pm 0.89$ & 0.007 \\
\hline & Second row & Backrow & $-0.76 \pm 0.74$ & 0.062 \\
\hline & (") & Halves & $-1.37 \pm 0.95$ & 0.012 \\
\hline & (") & Centres & $-0.59 \pm 0.86$ & 0.182 \\
\hline & (") & Back three & $-1.45 \pm 0.91$ & 0.008 \\
\hline & Backrow & Centres & $0.17 \pm 0.87$ & 0.685 \\
\hline & (") & Halves & $-0.61 \pm 0.96$ & 0.196 \\
\hline & " & Back three & $-0.74 \pm 0.92$ & 0.130 \\
\hline & Halves & '"' & $-0.13 \pm 1.07$ & 0.801 \\
\hline & $" '$ & Centres & $0.78 \pm 1.04$ & 0.137 \\
\hline & Back three & $" ?$ & $-0.91 \pm 1.01$ & 0.094 \\
\hline
\end{tabular}

${ }^{a}$ First positional group (left column) compared to the second (right column).

${ }^{\mathrm{b}}$ Effect sizes are that of the mean differences between positional groups.

c The Bonferroni correction was applied to account for multiple comparisons.

"'Indicates repeat group of that above.

of professionalism in the current international women's game (i.e. full time players train more, adapt to training better and phenotypic differences would more easily present in non-relative scaled physiological measures). While limited physiological data exists on international women's RU athletes, the present sample is representative of the wider international women's RU athletic population, in that the present anthropometric data (Tab. 1) aligns well with other women's Rugby World Cup 2006 and 2010 participants (Schick, Molloy, \& Wiley, 2008; Taylor, Fuller, \& Molloy, 2011). 


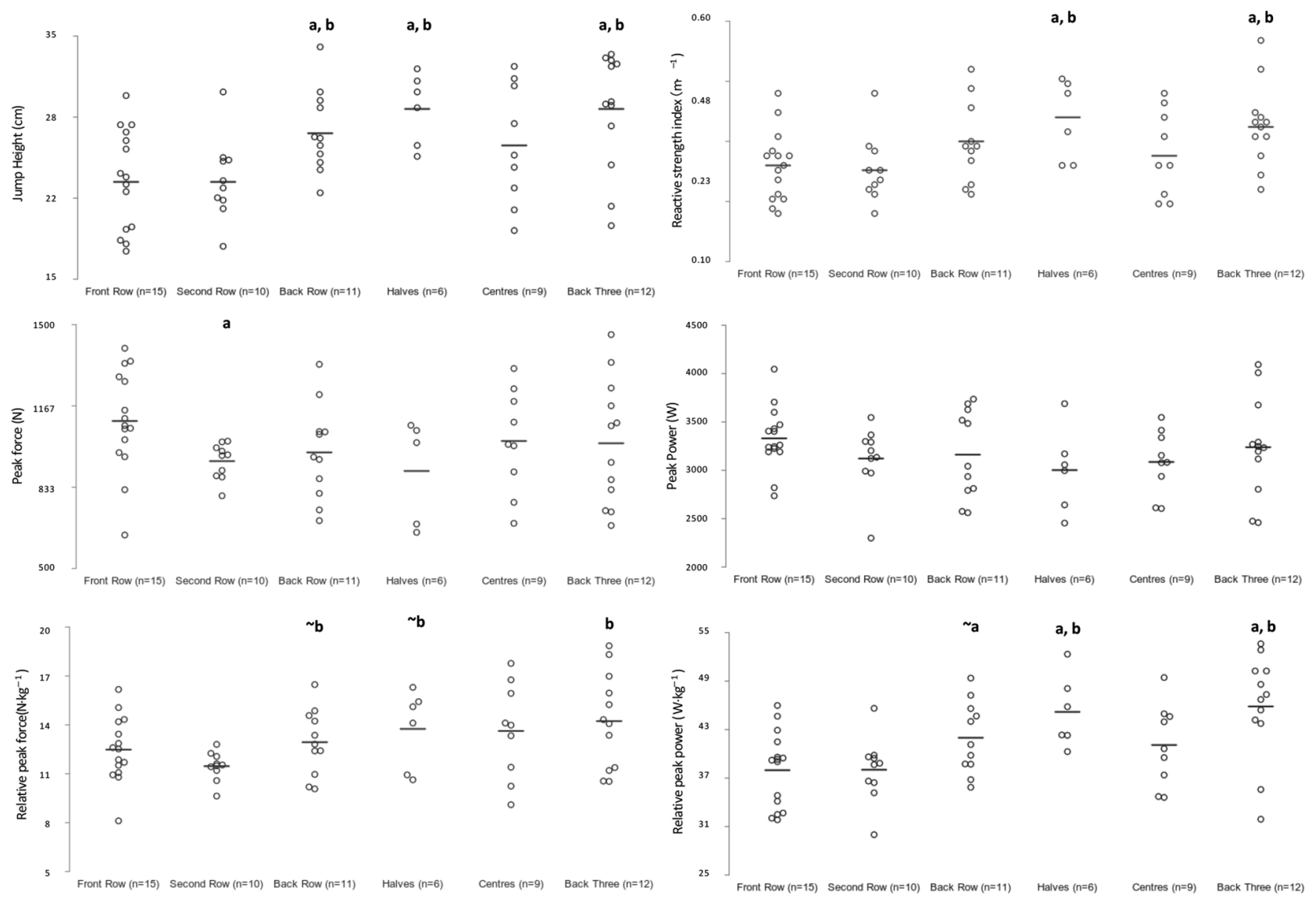

Fig. 2. RU individual data positional variation. "a" indicates null-hypothesis difference from front row, "b" second row $(p<0.05)$. "w" indicates a null-hypothesis tendency at $p<0.06$.

The present data in international women's rugby show that, while forwards had greater body mass compared to backs $(\sim 10 \mathrm{~kg})$, it did not translate into differences in lower-body net peak power $(\sim 40 \mathrm{~W}$ difference; Tab. 1$)$. This differs from the positional differentiation of peak power in the men's game, where forwards are substantially more powerful ( $\sim 400 \mathrm{w}$ difference; Brazier et al., 2018; Heffernan et al., 2017). However, after controlling for mass, international women's backs had a greater relative power output and these data mirrored the men's data (Tab. 1). To our knowledge, only two studies have investigated jump variables in women's RU athletes, one with a collegiate sample using the "Just Jump" jump mat system (n = 8; Lockie et al., 2016) and an elite South Africa Women's Rugby World Cup 2010 training squad using the "Vertec Jump Tester" ( $\mathrm{n}=32$; Hene et al., 2011). Both studies reported higher jump heights than the present study $(\sim 41 \mathrm{~cm})$ however, while there are a number of possible reasons for this (e.g. the sample), it is most likely that the significant variability in jump values compared to other technologies, including force platforms, explains these findings (such as that used in the present study: Buckthorpe, Morris, \& Folland, 2012; Dobbin, Hunwicks, Highton, \& Twist, 2017; McMahon, Jones, \& Comfort, 2016; Menzel et al., 2010; Muehlbauer, Pabst, Granacher,
\& Busch, 2017). Therefore, these studies are not comparable to the present data, which utilised a validated Hur Labs force platform (Dobbin et al., 2017). Therefore, the present study represents the best available jump kinetics data of elite women's RU, nonetheless significantly more work is needed to increase awareness of physical and performance characteristics of elite female rugby $7 \mathrm{~s}$ and $15 \mathrm{~s}$ athletes.

Antithetically, male RU athletes are physiologically similar between international level and the most immediate lower athletic level (Smart et al., 2013). However, international women's RU athletes (the only available data is for 7's athletes, however a similar dynamic can be inferred for the 15's game) are physiologically superior (better maximal speed, $\sim 1 \mathrm{~m} \cdot \mathrm{s}^{-1}$; neuromuscular recovery, $\sim 230 \mathrm{U} / \mathrm{L}$ creatine kinase; Yo-Yo fitness, $\sim 370 \mathrm{~m}$ ) to the sub-elites immediately below (Clarke, Anson, \& Pyne, 2015; Clarke et al., 2017; Smart et al., 2013; Vescovi \& Goodale, 2015). This should be a consideration for coaches and NGOs when promoting female athletes to international level and the present data suggests possible jump kinetic characteristics for athletes accelerating through the competitive levels. From a practical perspective, if athletes and coaches are unaware of the differences in physiological demands, both positionally and when 
accelerating from community rugby to representative RU, there is a potential injury risk. Less physically developed athletes are more likely to accrue musculoskeletal injury risk (e.g., dislocation, fracture, sprain/strain, stress fractures, tendonitis, bursitis, etc.) then those who are already physically prepared (Attwood, Roberts, Trewartha, England, \& Stokes, 2019; de la Motte, Gribbin, Lisman, Murphy, \& Deuster, 2017; de la Motte, Lisman, Gribbin, Murphy, \& Deuster, 2019; Duke, Martin, \& Gaul, 2017; Gabbett, Ullah, \& Finch, 2012). In a series of systematic reviews of physical phenotypes and musculoskeletal injuries, moderate-to-strong evidence was identified for muscle strength, power, endurance and sprint ability to predict ankle sprains, Achilles tendon, hamstring and contact (defined by physiotherapist report) injury (de la Motte et al., 2017, 2019). Therefore, developing an understanding of the physiological demands of international women's RU, and implementing appropriate practical changes, will inform athletes and coaches as to the required physiological capacity that may help prevent injury and may result in great match success (although this is yet to be empirically shown). Furthermore, recent data suggest that the relationship between training load and injury risk in $\mathrm{RU}$ follows an inverted U pattern (Cross, Williams, Trewartha, Kemp, \& Stokes, 2016). Therefore knowing, in advance, the physiological requirements typical of international athletes and gradually achieving these practical implications with appropriate training strategies, could aid in the transition from community/club to international rugby (in women's $\mathrm{RU}$ this can often be a rapid acceleration) that could impact to lower injury risk - which has been shown in other team sports (Malone et al., 2018).

Another consideration with women's RU, is that athletes frequently switch between playing position (70\% of the present sample report a secondary position); therefore, knowledge of the variation in physiological demands from the primary to secondary position, could be an indicator for coaches as to the possible player success (or potentially the likelihood/odds of injury). The present data provides achievable targets for athletes and coaches when considering these demands and may provide adaptive training specific targets. In fact, a recent systematic review of pooled Women's Rugby World Cup (2006 and 2010; 2014 and 2017 data is currently unpublished) shows that props and centres were the most commonly injured athletes and in the present data these two groups (front rows hereafter) have similar values, with data on the back/forward unit split inconsistent through the literature (King et al., 2019). The present study also collected data on secondary position statistics, however the sample was not powered $(46 \% ; \mathrm{n}=38)$ to investigate potential physiological differences between primary and secondary positions. The magnitude of the difference in physiological capacity between primary and secondary position could have a significant impact in potential injury susceptibility (given the data presented above; de la Motte et al., 2017, 2019; Duke et al., 2017; Gabbett et al., 2012). Currently, there have been no attempts to quantify these differences or identify if injury rates differ depending on weather a player is playing in their primary or secondary (outside of their primary positional group) position, but these data are highly warranted. Finally, these data are pre-competition values, assumed to be near to the athlete's physiological peak. Future research should investigate how these variables are subject to change (acutely and chronically) as a measure of fatigue or adaptation throughout an international season.

\section{Conclusion}

The present data provide important jump kinetic data of internationally competitive women's RU athletes, at unit and positional group level. Specifically, greater force and power variables were identified in the backrow, half back and back three positions, compared to front and second rows. These data can be used as a benchmark for nations and the development of athletes to international level, which could have important implications for injury risk. Future investigations should address this question in elite Women's RU and further consider the secondary position phenomena, as described above. Additionally, Women's RU athletes represent a unique population of female athletes, involved in a high velocity collision sport. Thus, important factors, such as menses and the effect of contraceptive medication should be included in future investigations, as both have significant impacts on muscle-tendon unit function and potentially injury susceptibility.

\section{Supplementary Material}

Table S1. Countermovement jump performance indicators by positional sub-group from women's Rugby World Cup (2017) competitors, presented as means \pm standard deviations.

The Supplementary Material is available at http:// science-motricite.org/10.1051/sm/2021013/olm.

\section{References}

Agar-Newman, D.J., Goodale, T.L., \& Klimstra, M.D. (2017). Anthropometric and physical qualities of international level female rugby sevens athletes based on playing position. Journal of Strength and Conditioning Research, 31(5), 13461352. DOI: $10.1519 /$ jsc.0000000000001167.

Attwood, M.J., Roberts, S.P., Trewartha, G., England, M., \& Stokes, K.A. (2019). Association of the Functional Movement Screen with match-injury burden in men's community rugby union. Journal of Sports Sciences, 37(12), 1365-1374. DOI: 10.1080/02640414.2018.1559525.

Baker, D. (2001). Comparison of upper-body strength and power between professional and college-aged rugby league players. Journal of Strength and Conditioning Research, 15(1), 30-35.

Brazier, J., Antrobus, M., Stebbings, G.K., Day, S.H., Callus, P., Erskine, R.M., Bennett, M.A., Kilduff, L.P., \& Williams, A.G. (2018). Anthropometric and physiological characteristics of elite male rugby athletes. Journal of Strength and Conditioning Research, 34(6), 1790-1801. DOI: 10.1519 /jsc.0000000000002827. 
Buckthorpe, M., Morris, J., \& Folland, J.P. (2012). Validity of vertical jump measurement devices. Journal of Sports Sciences, 30(1), 63-69. DOI: 10.1080/02640414.2011.624539.

Cahill, N., Lamb, K., Worsfold, P., Headey, R., \& Murray, S. (2013). The movement characteristics of English Premiership rugby union players. Journal of Sports Sciences, 31(3), 229-237.

Chavda, S., Bromley, T., Jarvis, P., Williams, S., Bishop, C., Turner, A.N., Lake, J.P., \& Mundy, P.D. (2018). Force-time characteristics of the countermovement jump: Analyzing the curve in Excel. Strength and Conditioning Journal, 40(2), $67-77$.

Clarke, A.C., Anson, J.M., \& Pyne, D.B. (2015). Neuromuscular fatigue and muscle damage after a women's rugby sevens tournament. International Journal of Sports Physiology and Performance, 10(6), 808-814. DOI: 10.1123/ijspp.2014-0590.

Clarke, A.C., Anson, J.M., \& Pyne, D.B. (2017). Game movement demands and physical profiles of junior, senior and elite male and female rugby sevens players. Journal of Sports Sciences, 35(8), 727-733. DOI: $10.1080 /$ 02640414.2016.1186281.

Cohen, J. (1988). Statistical power analysis for the behavioral sciences (2nd ed.). Routledge.

Cross, M.R., Brughelli, M., Brown, S.R., Samozino, P., Gill, N. D., Cronin, J.B., \& Morin, J. (2014). Mechanical properties of sprinting in elite rugby union and rugby league. International Journal of Sports Physiology and Performance, 10(6).

Cross, M.J., Williams, S., Trewartha, G., Kemp, S.P., \& Stokes, K.A. (2016). The influence of in-season training loads on injury risk in professional rugby union. International Journal of Sports Physiology and Performance, 11(3), 350-355. DOI: 10.1123/ijspp.2015-0187.

Cunningham, D.J., Shearer, D.A., Carter, N., Drawer, S., Pollard, B., Bennett, M., Eager, R., Cook, C.J., Farrell, J., Russell, M., \& Kilduff, L.P. (2018). Assessing worst case scenarios in movement demands derived from global positioning systems during international rugby union matches: Rolling averages versus fixed length epochs. PLoS One, 13(4), e0195197. DOI: 10.1371/journal.pone.0195197.

de la Motte, S.J., Gribbin, T.C., Lisman, P., Murphy, K., \& Deuster, P.A. (2017). Systematic review of the association between physical fitness and musculoskeletal injury risk: Part 2-Muscular endurance and muscular strength. Journal of Strength and Conditioning Research, 31(11), 3218-3234. DOI: $10.1519 /$ jsc.0000000000002174.

de la Motte, S.J., Lisman, P., Gribbin, T.C., Murphy, K., \& Deuster, P.A. (2019). Systematic review of the association between physical fitness and musculoskeletal injury risk: Part 3-Flexibility, power, speed, balance, and agility. Journal of Strength and Conditioning Research, 33(6), 1723-1735. DOI: $10.1519 /$ jsc.0000000000002382.

Deutsch, M., Kearney, G., \& Rehrer, N. (2007). Time-motion analysis of professional rugby union players during matchplay. Journal of Sports Sciences, 25(4), 461-472.

Dobbin, N., Hunwicks, R., Highton, J., \& Twist, C. (2017). Validity of a jump mat for assessing countermovement jump performance in elite rugby players. International Journal od Sports Medicine, 38(2), 99-104. DOI: $10.1055 / \mathrm{s}-0042-118313$.

Duke, S.R., Martin, S.E., \& Gaul, C.A. (2017). Preseason functional movement screen predicts risk of time-loss injury in experienced male rugby union athletes. Journal of Strength and Conditioning Research, 31(10), 2740-2747. DOI: 10.1519 /jsc.0000000000001838.

England Rugby. (2019). England Women announce contracts and squad. Retrieved from https://www.englandrugby.com/ news/england-women-contracts-red-roses-and-squad/.
Gabbett, T.J., Ullah, S., \& Finch, C.F. (2012). Identifying risk factors for contact injury in professional rugby league playersapplication of a frailty model for recurrent injury. Journal of Science and Medicine in Sport, 15(6), 496-504. DOI: 10.1016/ j.jsams.2012.03.017.

Goodale, T.L., Gabbett, T.J., Stellingwerff, T., Tsai, M.C., \& Sheppard, J.M. (2016). Relationship between physical qualities and minutes played in international women's rugby sevens. International Journal of Sports Physiology and Performance, 11(4), 489-494. DOI: 10.1123/ijspp.2014-0509.

Heffernan, S.M., Stebbings, G.K., Kilduff, L.P., Erskine, R.M., Day, S.H., Morse, C.I., McPhee, J.S., Cook, C.J., Vance, B., Ribbans, W.J., Raleigh, S.M., \& Williams, A.G. (2017). Fat mass and obesity associated (FTO) gene influences skeletal muscle phenotypes in non-resistance trained males and elite rugby playing position. BMC Genetics, 18(1), 1-9. DOI: 10.1186/s12863-017-0470-1.

Hene, N.M., \& Bassett, S.H. (2013). Changes in the physical fitness of elite women's rugby union players over a competition season. South African Journal of Sports Medicine, 25(2), 47-50.

Hene, N., Bassett, S., \& Andrews, B. (2011). Physical fitness profiles of elite women's rugby union players: physical fitness and training programme. African Journal for Physical Health Education, Recreation and Dance, 17(Supp 1), 1-8.

Hopkins, W. (2002). A new view of statistics: Effect magnitudes. Retrieved February, 14, 2005.

Hopkins, W.G., Marshall, S.W., Batterham, A.M., \& Hanin, J. (2009). Progressive statistics for studies in sports medicine and exercise science. Medicine and Science in Sports and Exercise, 41(1), 3-13. DOI: 10.1249/MSS.0b013e31818cb278.

IOC. (2017). Rugby History of Rugby at the Olympic Games. Retrieved from www.worldrugby.org/studies.

King, D., Hume, P., Cummins, C., Pearce, A., Clark, T., Foskett, A., \& Barnes, M. (2019). Match and training injuries in Women's Rugby Union: A systematic review of published studies. Sports Medicine. DOI: 10.1007/s40279-019-01151-4.

Lockie, R.G., Orjalo, A.J., Amran, V.L., Davis, D.L., Risso, F. G., \& Jalilvand, F. (2016). An introductory analysis as to the influence of lower-body power on multidirectional speed in collegiate female rugby players. Sport Science Review, 25 (1-2), 113-134.

Malone, S., Earls, M., Shovlin, A., Eddy, A., \& Winkelman, N. (2018). Match-play running performance and exercise intensity in elite international women's rugby sevens. Journal of Strength and Conditioning Research, Ahead of print. DOI: 10.1519 /jsc.0000000000002547.

McMahon, J.J., Jones, P.A., \& Comfort, P. (2016). A correction equation for jump height measured using the just jump system. International Journal of Sports Physiology and Performance, 11(4), 555-557. DOI: 10.1123/ijspp.2015-0194.

Menzel, H.J., Chagas, M.H., Szmuchrowski, L.A., Araujo, S.R., Campos, C.E., \& Giannetti, M.R. (2010). Usefulness of the jump-and-reach test in assessment of vertical jump performance. Perceptual and Motor Skills, 110(1), 150-158. DOI: 10.2466/pms.110.1.150-158.

Misseldine, N.D., Blagrove, R.C., \& Goodwin, J.E. (2018). Speed demands of womens rugby sevens match play. Journal of Strength and Conditioning Research, Ahead of print.

Muehlbauer, T., Pabst, J., Granacher, U., \& Busch, D. (2017). Validity of the jump-and-reach test in subelite adolescent handball players. Journal of Strength and Conditioning Research, 31(5), 1282-1289. DOI: 10.1519/jsc.0000000000001607.

Nyberg, C.C., \& Penpraze, V. (2016). Determination of anthropometric and physiological performance measures in elite scottish female rugby union players. International Journal of Research in Exercise Physiology, 12(1), 10-16. 
Ohya, T., Asami, K., Miyazaki, Y., Iwai, Y., Hirai, H., \& Ikeda, T. (2015). Anthropometric and physiological characteristics of Japanese elite women's rugby sevens players. Football Science, 12, 84-90.

Quarrie, K., Handcock, P., Waller, A.E., Chalmers, D., Toomey, M., \& Wilson, B. (1995). The New Zealand rugby injury and performance project. III. Anthropometric and physical performance characteristics of players. British Journal of Sports Medicine, 29(4), 263-270.

Quarrie, K.L., Hopkins, W.G., Anthony, M.J., \& Gill, N.D. (2013). Positional demands of international rugby union: Evaluation of player actions and movements. Journal of Science and Medicine in Sport, 16(4), 353-359.

Roberts, S.P., Trewartha, G., Higgitt, R.J., El-Abd, J., \& Stokes, K.A. (2008). The physical demands of elite English rugby union. Journal of Sports Sciences, 26(8), 825-833.

Schick, D.M., Molloy, M.G., \& Wiley, J.P. (2008). Injuries during the 2006 Women's Rugby World Cup. British Journal of Sports Medicine, 42(6), 447-451. DOI: 10.1136/ bjsm.2008.046672.

Sedeaud, A., Marc, A., Schipman, J., Tafflet, M., Hager, J.-P., \& Toussaint, J.-F. (2012). How they won Rugby World Cup through height, mass and collective experience. British Journal of Sports Medicine, 46, 580-584.

Sheppy, E., Hills, S.P., Russell, M., Chambers, R., Cunningham, D.J., Shearer, D., Heffernan, S., Waldron, M., McNarry, M., \& Kilduff, L.P. (2019). Assessing the whole-match and worst-case scenario locomotor demands of international women's rugby union match-play. Journal of Science and Medicine in Sport, 23(6), 609-614. DOI: 10.1016/j.jsams.2019.12.016.
Smart, D.J., Hopkins, W.G., \& Gill, N.D. (2013). Differences and changes in the physical characteristics of professional and amateur rugby union players. Journal of Strength and Conditioning Research, 27(11), 3033-3044.

Smart, D., Hopkins, W.G., Quarrie, K.L., \& Gill, N. (2014). The relationship between physical fitness and game behaviours in rugby union players. European Journal of Sport Science, 14 (Suppl 1), S8-S17.

Suarez-Arrones, L., Portillo, J., Pareja-Blanco, F., Saez de Villareal, E., Sanchez-Medina, L., \& Munguia-Izquierdo, D. (2014). Match-play activity profile in elite women's rugby union players. Journal of Strength and Conditioning Research, 28(2), 452-458. DOI: 10.1519/JSC.0b013e3182999e2b.

Tabachnick, B.G., Fidell, L.S., \& Ullman, J.B. (2014). Using multivariate statistics (Vol. 6). Boston, MA: Pearson.

Taylor, A.E., Fuller, C.W., \& Molloy, M.G. (2011). Injury surveillance during the 2010 IRB Women's Rugby World Cup. British Journal of Sports Medicine, 45(15), 1243-1245. DOI: 10.1136/bjsports-2011-090024.

Twist, C., \& Worsfold, P. (2015). The science of rugby. Abingdon, OX: Routledge.

Vescovi, J., \& Goodale, T. (2015). Physical demands of women's rugby sevens matches: Female athletes in motion (FAiM) study. International Journal of Sports Medicine, 94(11), 887-892.

Virr, J.L., Game, A., Bell, G.J., \& Syrotuik, D. (2014). Physiological demands of women's rugby union: time-motion analysis and heart rate response. Journal of Sports Sciences, 32(3), 239-247. DOI: 10.1080/02640414.2013.823220.

World Rugby. (2018). World Rugby year in review $201 \%$. Retrieved from http://publications.worldrugby.org/yearinre view2017/en/48-1.

Cite this article as: Heffernan SM, Neville R, Waldron M, Stewart R, Kilduff LP, Ditroilo M, \& Grainger A (2021) Positionspecific countermovement jump characteristics of elite Women's Rugby World Cup 2017 athletes. Mov Sport Sci/Sci Mot, 113, $27-37$ 